International Journal of Linguistics, Literature and Culture
Available online at https://sloap.org/journals/index.php/ijllc/
Vol. 5, No. 1, January 2019, pages: $43 \sim 53$
ISSN: $2455-8028$
https://doi.org/10.21744/ijllc.v5n1.582

\title{
Bali Tourism Advertisements: A Linguistic Analysis
}

CrossMark

Desak Putu Eka Pratiwi ${ }^{a}$

I Komang Sulatra ${ }^{b}$

Komang Dian Puspita Candra ${ }^{c}$

Article history:

Received: 27 July 2018

Accepted: 30 November 2018

Published: 9 January 2018

\section{Keywords:}

advertisement;

Balinese;

context;

linguistic features;

local values;

\begin{abstract}
Bali is very well known for its tourism which attracts many people all around the world with its magnificent nature and enchanting culture. Bali as the leading tourism destination in Indonesia is able to increase the welfare of its people from the tourism sector. Tourism development in Bali results in the growth of hotels, villas, and resorts in Bali. It challenges the owners of hotels or villas to promote their properties through advertisements in various media, including tourism magazines which are popular among travelers in Bali. The word choice is very crucial in the language of advertising and it becomes more effective when it fits the situational contexts. Language and contexts could not be separated in creating influential advertisement discourse. The aims of the study are: (a) to identify linguistic features used in accommodation advertisements; (b) to describe the situational contexts, and (c) to discover why these linguistic features are especially common in this situational context. The data of the study were taken from hotel, villa, and resort advertisements published on tourism magazines, such as Bali and Beyond, Bali Now and Hello Bali. The advertisements published in those magazines are highly competitive. In collecting the data, the researcher used observation method with note taking technique. The data were analyzed using a qualitative method by implementing the theory proposed by Biber and Conrad (2009). Results of the study are presented in formal and informal methods.
\end{abstract}

2455-8028 ${ }^{\circ}$ Copyright 2019. The Author. This is an open-access article under the CC BY-SA license (https://creativecommons.org/licenses/by-sa/4.0/) All rights reserved.

\section{Author correspondence:}

Desak Putu Eka Pratiwi,

STIBA Saraswati Denpasar, Indonesia.

Email address: desak.eka.pratiwi@gmail.com

\footnotetext{
a English Study Program, College of Foreign Languages, (STIBA) Saraswati Denpasar, Indonesia

${ }^{\mathrm{b}}$ English Study Program, College of Foreign Languages, (STIBA) Saraswati Denpasar, Indonesia

${ }^{\mathrm{c}}$ English Study Program, College of Foreign Languages, (STIBA) Saraswati Denpasar, Indonesia
} 


\section{Introduction}

Tourism is now the star of the economic growth in Bali. Bali is famous for its beautiful sandy beaches, lush green rice terraces and traditional Hindu culture. Attracted by this global reputation, Bali has long been a tourism hotspot, pulling in 3 million holidaymakers in 2012. Bali as the leading tourism destination in Indonesia is able to increase the welfare of its people from the tourism sector. Tourism development in Bali results in the growth of hotels, villas, and resorts in Bali. This phenomenon can be clearly seen in the mass media especially in Bali tourism magazines which consist of many advertisements promoting various accommodations in Bali, from low budget hotel to five stars and luxurious resorts (Astuti et al., 2018; Suryasa, 2016).

With the rapid economic growth and travel needs' increase, tourism advertisements have become a vital means for tourists to make a tour. The government and private companies in the tourism sector face challenges of creating marketing and advertising programs capable of communicating effectively with a diversity of target markets. Language has a powerful influence on people and their behavior (Oakes, 1998; O'Keeffe \& McCarthy, 2010). This is especially true in the fields of marketing and advertising. Word choice in marketing and advertising is absolutely critical. Visual content and design in advertising have a very great impact on the consumer, but it is language that helps people to identify a product and remember it. When advertisers spend millions of dollars each year, they indeed have tested every word they are going to use (Ritchie, 2004; Sneddon, 2007). They want their word choices to psychologically lead people to believe their product is the best, that it will change people's life. Skilled advertisers can get us to absorb their message unconsciously.

Crystal \& Biber et al., (1998), advertising language is a loaded language which is focused on persuading people to purchase products or services. This research generally aims at discovering the linguistic features of accommodation advertisements in Bali tourism magazines. Stevens (2004) \& Wenstøp (1980), it is crucial to uncover how the advertisers construct the message through wordplay and how the meaning transferred successfully to the readers. This will be done through a careful discourse analysis on all aspects of Bali tourism advertisements by using the theory of Register by Biber (2009), (2006). Taking Bali tourism advertisements as a case study, the research is expected to have practical implications for the tourism industry in Bali.

\section{Materials and Methods}

The data source of this study was taken from accommodation advertisements. The accommodation advertisements refer to the advertisements of hotels, villas, and resorts in Bali. The advertisements were taken from selected and high reputed Bali tourism magazines, such as Bali \& Beyond, Hello Bali and Bali Now magazine. They were chosen as the data source because they are the most popular and highly trusted tourism magazines in Bali. Therefore, many tourism companies put their advertisements in those magazines. The advertisers compete to create outstanding advertisements in term of lexical choice and visual effects. The language of advertising is commonly unique and extraordinary (Dyer, 2008; Morgan \& Pritchard, 2012). It is very interesting to analyze. In collecting the data, the researcher used observation method with note taking technique. The data were analyzed using a qualitative method by implementing the theory proposed by Biber \& Conrad (2009). Results of the study are presented in formal and informal methods.

\section{Results and Discussions}

The discussion is divided into three parts. Firstly, the analysis is focused on the situational context. It is followed by an analysis of linguistic features. Finally, it is ended with the functional interpretation.

\subsection{Situational Context}

The topic of the advertisements of is about accommodation in Bali since the data of the study are limited on accommodation advertisements in Bali. The addressors are the advertisers, which consist of different companies who promote their products and service through advertisements. While the addresses are the readers of the magazines which are mostly travelers or tourists. Most of the registers are produced by individuals who are readily identifiable. However, the addressors in the advertisement are less apparent. In many cases, the addressee can be an 
individual, as in a face-to-face conversation with a friend. Personal letters and e-mail messages are also often addressed to an individual. However, the advertisements have an un-enumerated set of addressees because it is impossible to specify the set of individuals who read a newspaper or magazine.

In term of interactiveness, the communication between the addressor and the addressees are less interactive because they did not do a face-to-face communication. In other words, the addressor and the addressees share a different place. The addressors are an institutional speaker whereas the addresses are public audiences. No personal relationship among them. The participants cannot respond to one another. The participants also have different degrees of shared background knowledge.

This advertisement is in the written mode. Obviously, producing an advertisement needs much money so it must be well prepared before it is widely published. This register has been carefully planned, revised, and edited. Generally, the communicative purpose of this advertisement is to promote the company's products and service. Specifically, it aims at persuading the addressees to buy the product. Another parameter relating to purpose is factuality. The addressors tried to show some facts about the product by showing the details and describing them one by one in a very persuasive way. So the addressees will be attracted and interested in that product.

\subsection{Linguistic Features}

Reppen et al., (2002), the language of advertisements is very complex, both in term of word choice and sentence structures. This subchapter will explain salient linguistic features used in accommodation advertisements in Bali tourism magazines. The advertisement is a persuasive communication which can change people's mind and behavior. An advertisement is created to attract people's attention. The advertisements are delivered in attractive words or sentences to make people curious and interested in the products. The advertisers will build a positive image of the products to convince people to choose or buy their products.

\section{a) Word Choice}

The use of the pronoun is very crucial in accommodation advertisements. This research examines the salient pronoun used in accommodation advertisements. The salient pronouns found in the data are we and you, as seen in the following sentences.

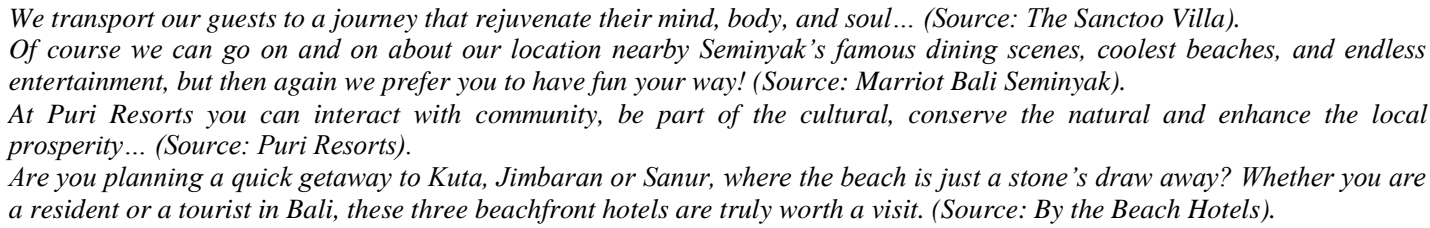

Pronoun we in the example above refers to the advertisers. It uses a plural pronoun instead of the singular pronoun in order to show that many people are responsible for the truth of the advertisements' content. The use of pronoun we create a closer and more intimate relationship between the advertisers and the readers, although they even do not meet or know each other. It will make the readers feel more comfortable and shorten the distance between the addressors and addressees. It also sounds more formal in comparison with the use of pronoun $I$ for instance. The second pronoun which commonly used in accommodation advertisements is you which refers to the readers.

Additionally, it can be seen that accommodation advertisements typically use particular verbs. The most frequently used verbs in accommodation advertisements are taken, stay, enjoy, come and experience. Those verbs are commonly invitation for readers to come, enjoy and experience an unforgettable stay in Bali. The use of the verb take can be seen in the following examples.

Discreet yet attentive service from dedicated team butlers takes care of every need. (Source: The Kayana Hotel).

Delightful mountain cabins for singles, couples, or families with wooden floors, bathtubs, TV, WIFI, private balconies, great views and gardens that take your breath away. (Source: Strawberry Hill Hotel and Restaurant).

The first sentence shows how the advertisers try to convince the readers that when they stay in Kayana Hotel, they will be served by dedicated team butlers who will never disappoint them. It emphasizes the perfect service they have, the butlers will take care of the guest' every single need. While the second sentence shows a different way to attract people to stay in the hotel. It highlights the facilities of the hotel which can be used by the guest to

Pratiwi, D. P. E., Sulatra, I. K., \& Candra, K. D. P. (2019). Bali tourism advertisements: a linguistic analysis. International Journal of Linguistics, Literature and Culture, 5(1), 43-53. https://doi.org/10.21744/ijllc.v5n1.582 
comfort their stays, such as wooden floors, bathtubs, TV, WIFI, private balconies, great views and gardens which are breathtaking and all in one place. And here are the examples of the use of verb stay that can be seen in the following sentences.

\author{
Stay smart, stay sensible and stay Sens for each and every stay! \\ (Source: Sens Hotels and Resorts). \\ Never just stay, stay inspired. (Source: Conrad Bali). \\ Stay in cozy comfort, while you explore Bali’s lake district. (Source: Strawberry Hill Hotel and Restaurant).
}

The verb stay is often used in accommodation advertisements. It is very obvious since the advertisements offer a place to stay in Bali during the holiday. The examples show the use of the verb stays repeatedly in the first sentence. The repetition of verb stay is typically used to show quantity, emphasis or for esthetics. The first sentence implicitly said that if you are smart you must stay in Sens Hotels and Resorts. And in the second sentence, there is also repetition of verb stay which delivers a message that when you choose a hotel, choose the one which can give you not only a stay but also inspiration of life like Conrad Bali. While the last example simply invites the readers to stay in a comfortable and cozy place near the lake in Strawberry Hill Hotel and Restaurant. Another frequently used verb is the verb enjoy which can be seen in the following sentences.

Enjoy little ubud in the trendy area of seminyak. (Source: Hotel Villa Lumbung).

Enjoying the comfortable stay with us. (Source: Puri Resort).

You can enjoy the white sands of Kubu beach and receive priority access to rock bar. (Source: Rimba Jimbaran Bali).

The verb enjoys in the sentences above are basically used to invite the readers to enjoy their stay in various hotels, villas, and resorts in Bali with many different offers and concepts which are free to choose. For instance, in the first sentence, the hotel which located in Seminyak offers little Ubud in the trendy area which actually contradictive but interesting. While in the second sentence, the resort which located in Ubud offers comfortable stay which enables the guests to easily mingle with local people, quite a unique concept. Differ from the last sentence which offers white sand beach view and priority access to the most iconic bar in Bali, Rock Bar. It has been heralded as one of the world's best bars by authoritative sources including CNN and The New York Times, and in 2011 was voted Bali's Best Sunset Venue in The Yak magazine readers' awards. This offer becomes very tempting for the readers. All companies competing to promote their products and show their own specialties which sometimes make the readers confused to choose. It shows that the competition in advertising is very tight so that language has an important role to persuade the readers, attract attention and change people's mind. Other examples can be seen in the following sentence, using a verb come and experience.

Comehome to comfort \& warmth. (Source: Awarta Villa \& Spa).

Don't just dream of the ultimate getaways, come and experience it yourself at The Sanctoo Villa. (Source: The Sanctoo Villa). Embracing nature, experiencing culture(Source: The Sanctoo Villa).

The first sentence shows that the advertiser persuades the readers to come and stay at Awarta Villa and Spa by saying that it has a homey atmosphere which can make you feel like home when you stay there. It gives you comfort and warmth as a family does at home. While the second sentence seems stronger and demanding since it uses an imperative sentence. It emphasizes not to waste time dreaming of ultimate getaway, it's better to come and experience it which seems true. It indirectly gives the command for the readers to take a quick decision. And the last sentence shows how the advertiser arises the readers' curiosity by using Bali's beautiful nature and enchanting culture as their attraction. When people are curious they will come to see and stay in that villa.

Adjectives are also frequently used in accommodation advertisements, such as new, romantic, best and luxurious. The example can be seen in the following sentences.

Master the art of luxurious living at Rimba Jimbaran Bali by Ayana"s brand new tower featuring 120 stylish guest rooms and suites. (Source: Rimba Jimbaran Bali).

The Legian Bali introduces a whole new living experience on their exclusive villa collection at the club at The Legian Bali. (Source: The Legian Bali).

The use of the adjective new in most of the accommodation advertisements shows that the keyword to promote accommodation is offering something new and fresh. The readers will be much more interested in trying something new rather than something mainstream. That is why then most of the advertisements use the word new to show that 
their product is different and people need to try it. Moreover, there are even too many accommodations to choose in Bali so that the company needs to create something extremely new to attract the guests and show their own identity. The other frequently used adjective is romantic as seen in the following sentences.

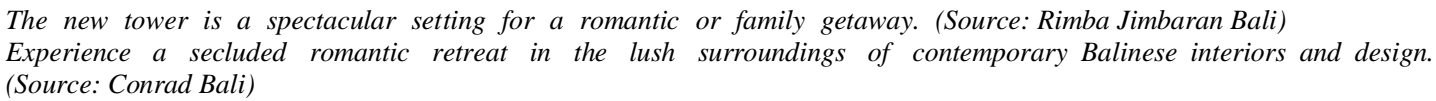

The word romantic is compatible to describe Bali as an exotic island which is often visited by couple or honeymooners. The advertisers are very sensible and use it as a tool to attract people. Many accommodation advertisements use it to promote their place since some people need a place which is able to give them privacy and romantic atmosphere to celebrate their special moments. It will be effective since many public figures all over the world even held their wedding in Bali. It means that all the world admit that the island is truly romantic. It is not surprising that many accommodations claim that their place is as romantic as the island. Evidently, most of the hotels in Bali not only offer accommodation but also wedding and honeymoon package. It implicitly shows that the advertisers have known market's need and they try to provide it as well. That is why the word romantic plays an important role to persuade readers to choose the product.

Another adjective which frequently used in accommodation advertisements is best which basically describing the quality of the products on the advertisements. The example can be seen in the following sentence.

Experience a heavenly dining at our two award-wining venues; winner of Best Mediterranean Restaurant for now! Bali's Best Restaurant, Bar and Café Awards 2016. (Source: Padma Resort Ubud)

The use of the word best implies self-confidence and optimism. Many advertisements use it to show that they are the number one accommodation in Bali, no place better than their place. They claim that they have the top quality of accommodation in Bali which includes all facilities they have so that the readers will be interested and want to stay there. As shown by the sentence above in which the hotel promotes its restaurant which awarded as Bali's Best Restaurant, Bar and Café Awards 2016. Then this award is used to show their standard and quality in order to attract people attention since all people seek for good quality for a comfort stay. The use of word best also aims at creating a positive image of the products.

The word luxurious is also often used in accommodation advertisements which highlighted the prestige of the accommodation they offered, as seen in the following examples.

The arts of luxurious living at Rimba Jimbaran Bali by Ayana. (Source: Rimba Jimbaran Bali)

Well-appointed interiors and chic contemporary décor make a luxurious home away from home. (Source: The Kayana)

People commonly tired of their daily routines or work and need an escape. They seek for something different, they want to pamper themselves by living in a luxurious and relaxing place. The advertisers use the word luxurious to describe that they offered an extraordinary place to stay which is also very exclusive and high class. So that the guests who stay there will feel the different atmosphere from their daily life. The advertisements implicitly said that they will make you feel as if you lived in a palace which full of elegant furniture and facilities, good food and excellent service. This offer must be very interesting and persuading.

\section{b) Sentence Structures}

Based on data of this research, it is found that accommodation advertisements consist of various types of a sentence such as declarative, imperatives, interrogatives and exclamatory. Here are the examples of the declarative sentence.

We transport our guests to a journey that rejuvenate their mind, body and soul in a tranquil surrounds of the nature's beauty and vibrant culture of Bali. (Source: The Sanctoo Villas \& Spa)

Puri Resorts offer a home to experience the uniqueness and the richness of culture, the wonderful of panoramic, and the Balinese hospitality while sustaining the island of Bali. Puri Resorts are located in outskirts of Traditional Balinese Village, surrounded by the natural, away from hustle bustle of the city. At Puri Resorts you can interact with community, be part of the cultural, conserve the natural and enhance the local prosperity while enjoying the comfortable stay with us. (Source: Puri Resort)

Most of the sentences above are in form of statements which basically describing the details of the products. As seen in the first example which telling the readers that the Sanctoo villas and spa provides a living experience which

Pratiwi, D. P. E., Sulatra, I. K., \& Candra, K. D. P. (2019). Bali tourism advertisements: a linguistic analysis. International Journal of Linguistics, Literature and Culture, 5(1), 43-53. https://doi.org/10.21744/ijllc.v5n1.582 
is able to refresh people mind, body, and soul. It is also located in a beautiful surrounding which also close to local life where culture can be observed easily. While the second example describes in a very detailed way about the uniqueness of the resorts. The sentences state that Puri Resort enables the guests to explore Balinese nature and culture. The sentences also describe the strategic location of the resorts which is away from hustle bustle of the city so it can give new and relaxing atmosphere for the guests. The sentences implicitly saying that the resort is not only unique in term of its location and surrounding but also has a unique concept of living.

The other type of sentence is an imperative sentence. It gives a command or makes a request. It usually ends with a period but can, under certain circumstances, end with an exclamation point. The example can be seen in the following sentences.

Don't just dream of the ultimate gateways, come and experience it yourself at The Sanctoo Villa. (Source: Sanctoo Villa) Never Just Stay, Stay Inspired. (Source: Conrad Bali)

In the first example, the imperative sentence is used for intimidating the readers not to just dream about the ultimate holiday. The advertiser implicitly gives the command for the readers to come and experience the ultimate gateways at the Sanctoo villa which offers not just a place to stay but also brings the guests to get closer to Balinese nature and culture. The second sentence tells the readers to choose accommodation which not only provides a comfortable place to stay but also inspiring. The hotel which is located in a strategic spot which gives the guests a chance to enjoy the sea and romantic sunset. A relaxing atmosphere which can refresh body and soul. It gives inspiration and relaxation at the same time.

The advertisements also use interrogative sentences which can be categorized as rhetorical questions since the questions do not require any answers. They are used to encourage the readers to think and ask themselves and then take quick decisions. The example can be seen in the following sentences.

\footnotetext{
Are you planning a quick getaway to Kuta, Jimbaran or Sanur, where the beach is just a stone's throw away? Whether you are a resident or a tourist in Bali, these three beachfront hotels are truly worth a visit. (Source: By The Beach Hotel) Are you the ONE? Experience more about New Urban Legian. (Source: The One Legian Hotel)
}

Although it is in a question form, the first sentence implicitly tells the readers that when they plan to visit the area of Kuta, Jimbaran or Sanur they have to visit those beachfront hotels. The hotels are spread over the most favorite spots in Bali where tourists can enjoy activities on the beach, which also offer a beautiful view of the sunset. By asking questions, it leads the readers to think and consider to stay at By the Beach hotel. While the second sentence asks the readers, "Are you the ONE", which can be interpreted as a question which leads the readers to answer "Yes". When the readers said Yes, it means that they have made the decision to choose The One Legian Hotel. Rhetorical questions are considered as an effective way in persuading the readers to choose or buy products on the advertisements.

Besides those three types of sentence, the salient linguistic features of accommodation also can be seen in the use of active vs. passive sentence, as shown in the following examples.

Table 1

Active and Passive Sentences

Active Sentences

(Source: Vasanti Hotel)

Puri Resorts offer a home to experience the uniqueness and the richness of culture... (Source: Puri Resorts)

We transport our guests to a journey that rejuvenate their mind... (Source: The Sanctoo Villa)

\section{Passive Sentences}

Here, Bali's nature, culture and tranquility are

blended seamlessly...

(Source: The Sanctoo Villa)

RIMBA Jimbaran Bali by Ayana is fully integrated with sister Hotel Ayana Resort and Spa Bali. (Source: Rimba Jimbaran Bali)

Artfully designed and surrounded by treetop and ocean views... (Source: Rimba Jimbaran Bali) 
In term of active and passive voice, active voice occurs more frequently than the passive one. As seen in the examples, if the agent or the action is the main concern of the sentence, the 'active' form of the verb is used. On the other hand, if the recipient of the action is the main concern of the sentence, the 'passive' form of the verb is used. The advertisers tend to use the active form since most of the advertisements more concern on the agent of the sentence. Obviously, the agent in the sentence found in advertisements is the product itself. In addition, the sentence also focuses on the action. The action means what the product can do or give for the users. The recipient is not the main concern of the sentences in advertisements since it could be anyone.

\section{c) Rhetorical Devices}

The finding shows that accommodation advertisements also frequently use figurative language in order to create particular effects. There are various types of figurative language used in accommodation advertisements, such as personification, hyperbole, synecdoche, and metaphor. The examples will be presented as follows.

Personification is a figure of speech where human qualities are given to animals, objects or ideas. In the arts, personification means representing a non-human thing as if it were human. In easy language, personification is just giving an example of a living being for a non-living thing. "The wind shouted". Obviously, the wind cannot shout, only people can. This is what is called personification. Here are the examples are taken from the data.

Three beachfront hotels in three different areas for a lazy weekend in Bali. (Source: By The Beach Hotel)

Warm sunshine kisses your face as you prop up your feet by the pool and let time idle away. (Source: Conrad Bali)

The first sentence shows that the writer gives human attribute to a non-human thing. The writer gives attribute lazy for the word weekend which is a non-human thing. It is used to describe a condition or a moment when people just do nothing on that day, just enjoy their free time. The word lazy is actually referred to human characteristics but in that sentence, it is used for explaining the word weekend. It aims at creating an aesthetic and persuasive effect for the readers. In addition, the second sentence also consists of personification as seen in "Warm sunshine kisses your face..." in which the writer gives human attribute 'the ability to kiss' for sunshine which is a non-human thing. It gives great effect for readers in comparison with the ordinary way of expressing the same message. It sounds more interesting and persuading. It can build a positive image of the product.

Hyperbole is the use of exaggeration as a rhetorical device or figure of speech. As a figure of speech, it is usually not meant to be taken literally. Hyperbole may also be used for instances of such exaggerations for emphasis or effect. Hyperboles are often used in casual speech as intensifiers, such as saying "the bag weighed a ton". Hyperbole makes the point that the speaker found the bag to be extremely heavy, although it was nothing like a literal ton. The examples found in the data of this research can be seen as follows.

An enchanting heaven of discreet luxury and charm. (Source: Maison Aurelia Hotel)

Heaven in the heart of Kuta. (Source: Poppies Cottages \& Restaurants)

Both of sentences above use the word heaven to describe the quality of their products. As we know heaven in the definition is a place regarded in various religions as the abode of God (or the gods) and the angels, and of the good after death, often traditionally depicted as being above the sky. In other words, the word heaven, in this case, is used to describe a wonderful place where you can find and experience beautiful things. It is used to attract people to come and stay at that place. Understanding hyperboles and their use in context can further one's ability to understand the messages being sent from the speaker. The use of hyperboles generally relays feelings or emotions from the speaker, or from those who the speaker may talk about. Hyperbole can be used in a form of humor, excitement, distress, and many other emotions, all depending on the context in which the speaker uses it.

Synecdoche is a figure of speech in which a term for a part of something refers to the whole of something or vice versa. A synecdoche is a class of metonymy, often by means of either mentioning a part for the whole or conversely the whole for one of its parts. Examples from common English expressions include "bread and butter" (for "livelihood"), "suits" (for "businessmen"), and "boots" (for "soldiers") (pars pro toto), or conversely "America" (for "the United States of America") (totum pro parte). Here are the examples are taken from the data.

Morning spirit from Lumbung where a million of smiles await you home. (Source: Hotel Villa Lumbung) Located in the heart of the fashionable Seminyak district. (Source: The Kayana Villa)

As seen in the first sentence, the writer used the word smile in mentioning a part for the whole. Smile is part of the human as a whole. It is used to represent human's hospitality in giving service to the guests at the hotel. Smile

Pratiwi, D. P. E., Sulatra, I. K., \& Candra, K. D. P. (2019). Bali tourism advertisements: a linguistic analysis. International Journal of Linguistics, Literature and Culture, 5(1), 43-53. https://doi.org/10.21744/ijllc.v5n1.582 
represents warmth and friendliness. Everyone will feel comfortable when they stay in a place which surrounded by the people who make them feel like home. While in the second sentence, the writer used the word heart as part of the human body which is the center of blood circulation which also means the center of life. When the writer used the word heart in the second sentence, it shows that the villa is located in the center of Seminyak area, the most important and strategic place where people can easily get everything they need.

The metaphor is a figure of speech that makes an implicit, implied, or hidden comparison between two things that are unrelated, but which share some common characteristics. In other words, a resemblance of two contradictory or different objects is made based on a single or some common characteristics. In simple English, when you portray a person, place, thing, or an action as being something else, even though it is not actually that "something else," you are speaking metaphorically. For example, the phrase, "My brother is the black sheep of the family," is a metaphor because he is not a sheep, nor is he black. However, we can use this comparison to describe an association of a black sheep with that person. A black sheep is an unusual animal, which typically stays away from the herd, and the person being described shares similar characteristics. It actually makes an implicit or hidden comparison and not an explicit one. One example found in the data can be seen in the following sentence.

Are you planning a quick getaway to Kuta, Jimbaran or Sanur, where the beach is just a stone's throw away? (Source: By The Beach Hotel)

The underlined expression is an implied comparison. It compares stone's throw away with distance. It implicitly means that the hotel is very close to the beach. It also represents the strategic location of the hotel; it is a front beach hotel where the guest can relax by seeing the ocean or watch the sunsets. In addition, Kuta, Jimbaran or Sanur are very famous with their exotic beaches and it is very interesting that the hotels are located exactly near the hottest spot in Bali. It sounds more convincing and persuading when the writer using figurative language in expressing particular ideas than using a sentence which carries literal meaning. It also gives strong effects on the readers. They will feel more excited to visit those hotels which offer an extraordinary place to stay.

\subsection{Functional Interpretation}

Word choice is basically based on the topic. Since the topic is about accommodation in Bali, the words are closely related to this topic. The text shows some words which commonly related with accommodation, holiday and the uniqueness of Bali island, for instances, guests, tourists, journey, getaway, beach, a visit, hospitality, nature's beauty, Balinese culture, and many more. The data shows that the word choice and sentence structures in accommodation advertisements are formal since the target readers are people with high social status who afford to pay the high price.

In term of the personal pronoun, the advertisers mostly use pronoun we which refers to the company itself which offer the products through the advertisements. Research shows that the little word we can make a big difference in attitudes toward brands. It could increase a sense of closeness between the consumer and the brand. In addition, the use of the pronoun ' $y o u$ ' is also pervasive in accommodation advertisements which refers to the readers. Through the use of the pronoun ' $y o u$ ', advertisers manage to appeal to a wide audience and create an effect of addressing every customer personally.

Channel and setting also crucial in register analysis. The message is in written mode and delivered through printed media, tourism magazines. In this kind of communication, the advertisers and readers do not share the same place and time because the addressor and the addressees do not interact in face-to-face communication. Based on its communicative purposes, different types of sentence used in accommodation advertisements also have different communicative purposes. For instance, the use of declarative sentences basically aims at describing details of the products and explaining the quality or uniqueness of the products. Imperative sentences are commonly used to give the command for readers to come, to visit or to stay in the hotel, villa or resorts on the advertisements. While the interrogative sentences in advertisements are usually kind of rhetorical questions which do not need any answers. They are used to encourage the readers to think and ask themselves and then take quick decisions regarding the offers proposed by the advertisers. In general, all of them mainly have one purpose, to persuade the readers to buy the products. 


\section{Conclusion}

Based on the explanation above it can be concluded that accommodation advertisements have a high register since the advertisers use formal linguistic features more frequently than the informal ones. Obviously, it is influenced by the situational context, such as participants and relationship among them, channel, production circumstances, setting, communicative purposes, and the topic. In the advertisements, the addressor and the addressees do not have direct interaction and both do not know each other. That is why the addressors tend to use a formal pronoun to denote themselves and to address the addressees. Besides, communicative purposes are also considered in constructing those registers. Generally, advertisements aimed at persuading people to buy their product. Therefore, the addressors tend to use formal nouns to describe the detail of the product. Most of the advertisements used persuasive sentences to promote their product and to convince the target audiences to buy their product. Formal nouns are typically used in careful, edited writing. In this case, advertisements are also a kind of well-prepared register. So that formal words are used more often than the informal one.

\section{Conflict of interest statement and funding sources}

The authors declared that they have no competing interest. The study was financed by Ministry of Research, Technology, and Higher Education of the Republic Indonesia.

\section{Statement of authorship}

The authors have a responsibility for the conception and design of the study. The authors have approved the final article.

\section{Acknowledgments}

We would like to show our gratitude to the Almighty God for His blessing that this research can be completed at the end of this year (2018). This research was fully funded by Ministry of Research, Technology, and Higher Education of the Republic Indonesia. This paper is part of two years' research on language of advertisement used in Bali tourism advertisements. We also thank Bali Tourism Board for supporting this research by providing valuable data and information needed. In addition, we thank Head and Vice Head of College of Foreign Languages (STIBA) Saraswati Denpasar, Bali-Indonesia for always motivating us and letting us use campus' facilities during the research. We are also immensely grateful to Heru P. Ardi for technically helping us in finishing our project and the final report. We thank our colleagues who provided insight and expertise that greatly assisted the research, although they may not agree with all of the interpretations/conclusions of this paper. This paper is far from perfect. For this reason, constructive thoughtful suggestion and critics are welcomed.

Pratiwi, D. P. E., Sulatra, I. K., \& Candra, K. D. P. (2019). Bali tourism advertisements: a linguistic analysis. International Journal of Linguistics, Literature and Culture, 5(1), 43-53. https://doi.org/10.21744/ijllc.v5n1.582 


\section{References}

Astuti, N. N. S., Ginaya, G., \& Susyarini, N. P. W. A. (2018). Designing Bali tourism model through the implementation of tri hita karana and sad kertih values. International Journal of Linguistics, Literature and Culture, 5(1), 12-23. https://doi.org/10.21744/ijllc.v5n1.461

Biber, D. (2006). University language: A corpus-based study of spoken and written registers (Vol. 23). John Benjamins Publishing.

Biber, D., \& Conrad, S. (2009). Register, genre, and style. Cambridge University Press.

Biber, D., Conrad, S., \& Reppen, R. (1998). Corpus linguistics: Investigating language structure and use. Cambridge University Press.

Crystal, D. The Cambridge encyclopedia of language (Vol. 1, p. 987). Cambridge: Cambridge University Press. https://doi.org/10.1017/S0266078400013237

Dyer, G. (2008). Advertising as communication. Routledge.

Morgan, N., \& Pritchard, A. (2012). Advertising in tourism and leisure. Routledge.

Oakes, M. P. (1998). Statistics for Corpus Linguistics. Edinburgh Textbooks in Empirical Linguistics.

O'Keeffe, A., \& McCarthy, M. (Eds.). (2010). The Routledge handbook of corpus linguistics. Routledge.

Reppen, R., Fitzmaurice, S. M., \& Biber, D. (Eds.). (2002). Using corpora to explore linguistic variation (Vol. 9). John Benjamins Publishing.

Ritchie, G. (2004). The linguistic analysis of jokes. Routledge.

Sneddon. (2007). Colloquial Jakartan Indonesian. Canberra: National Australian University Press.

Stevens, A. M. (2004). A comprehensive Indonesian-English dictionary. PT Mizan Publika.

Suryasa, I. W. (2016). Figurative Language Found in Printed Advertisement. International Journal of Linguistics, Literature and Culture, 2(1), 29-38.

Wenstøp, F. (1980). Quantitative analysis with linguistic values. Fuzzy sets and systems, 4(2), 99-115. https://doi.org/10.1016/0165-0114(80)90031-7 


\section{Biography of Authors}

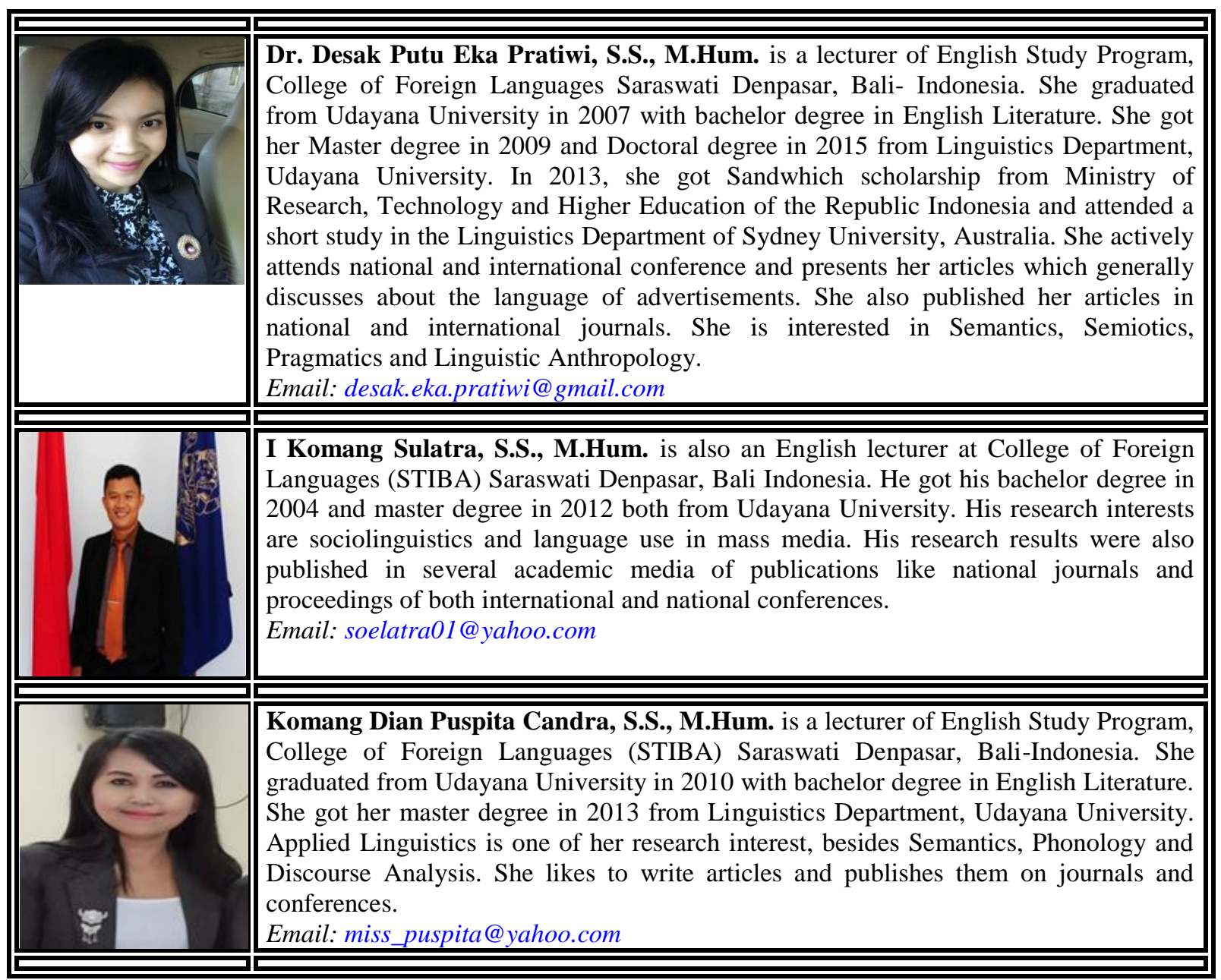

Pratiwi, D. P. E., Sulatra, I. K., \& Candra, K. D. P. (2019). Bali tourism advertisements: a linguistic analysis. International Journal of Linguistics, Literature and Culture, 5(1), 43-53. https://doi.org/10.21744/ijllc.v5n1.582 